Rafael Kretschmer, ${ }^{1,}$, Vanusa Lilian Camargo de Lima ${ }^{1}$, Letiane Nascimento da Ponte ${ }^{1}$, Tiago Marafiga Degrandi', Lúcia do Canto Vinadé ${ }^{1}$, Adriano Luis Schünemann', Analía Del Valle Garnero $^{1}$, Ricardo José Gunski ${ }^{1}$

\title{
NOR- bearing as a plesiomorphic characteristic in Mimus saturninus (Passeriformes Mimidae)
}

\begin{abstract}
The order Passeriformes is the largest group of species karyotyped among birds, however little is known about the cytogenetic of the Mimidae family, registering only karyology basic data (giemsa staining). The aim of this study was to analyze the chromosomal complement from the species Mimus saturninus by conventional staining and differential chromosome banding. Diploid number and chromosome morphology were determined, as well as the distribution pattern of constitutive heterochromatin (CBG-banding), GTG-banding andAgNOR staining (NORs). The Chalk-browed Mockingbird has $2 n=80$. The first and fourth pairs are submetacentric and the second, third and fifth are acrocentric. The remaining chromosomes pairs of the complement have telocentric morphology. The $Z$ chromosome is submetacentric and the $W$ is metacentric. CBG-banding showed positive staining in the pericentromeric region of most macrochromosomes and microchromosomes and also at $Z$ chromosome, differently from $W$ chromosome which appeared totally heterochromatic. The GTG-banding was similar to Gallus gallus and in other species which have already been GTG-banded. The NORs were identified in a pair of microchromosomes characterized by presenting a remarkable secondary constriction. This can be considered as a plesiomorphic characteristic for M. saturninus once baseline groups (Paleognathae) also showed a pair of microchromosomes bearing NORs.
\end{abstract}

Key words: karyotype, macro and microchromosomes, chromosome banding.

\footnotetext{
*Autor para correspondência

${ }^{1}$ Universidade Federal do Pampa, Rio Grande do Sul - Brasil. *email rafa.kretschmer@hotmail.com
} 


\section{INTRODUCTION}

The karyotype description of all species is crucial to map the genome. In addition, a karyotype providesvaluable information about genetic characteristics of an animal or cell line (Masabanda et al. 2004) and for phylogenetic and evolutionary analysis as well (Pieczarka and Nagamachi 2004). The birds karyotype is characterized by having a high diploid number $(2 n=78-80)$, a few pairs of macrochromosomes and many pairs of microchromosomes (Christidis 1990). The difficulty in distinguishing chromosomes, due to the presence of microchromosomes, does not occur for most of other classes in which chromosomes can be distinguished easily by techniques of classical or molecular cytogenetic (Masabanda et al. 2004). Due to these complexities, few works are conducted inbirds cytogenetic, for instance, less than $14 \%$ of the Brazilian birds are known through cytogenetic studies (Santos and Gunski 2006). Thus, more information is necessary to identify chromosomal rearrangements that had occurred during the speciation in order to understand the karyotype evolution of this class.

The precursor in birds cytogenetic studies was Guyer (1900), which examined the spermatogenesis of doves and hybrids. In Brazil, pioneering work was done by Aguiar, in 1965 . Since the 70th decade methodology has been improved with the advent of classical cytogenetic techniques, such as banding with barium hydroxid and silver staining. The use of these techniques allowed a significant increase in detection, interpretation and understanding of chromosomal rearrangements and also reveal important aspects of constitutive heterochromatin and nucleolus organizer regions (NOR) (Correia et al. 2009). Recently, analyzes with fluorescence in situ hybridization (FISH) have been used as a complement of conventional methods used to identify chromosomal rearrangements (De Oliveira et al. 2005). However, due to the high cost and complexity in performing FISH techniques, prior application of classical cytogenetic analysis and chromosome banding,in order to choose the right chromosomal probes, contribute significantly to obtain satisfactory results (De Oliveira et al. 2006).

The chromosomal characterization by classical and molecular cytogenetics has revealed important information about the evolutionary state of different groups of birds in relation to the ancestor of this class. For example, the presence of only one chromosome pair bearing $18 / 28 \mathrm{~S}$ rDNA sequences in species of the Cathartidae family (Gymnogyps californianus, Sarcoramphus papa, Cathartes aura and Cathartes burrovianus) is considered as a plesiomorphic state (primitive state) in this family (Raudsepp et al. 2002 Tagliarini et al. 2009). This assumption is based at the observation that NOR-bearing chromosomes correspond to pair 16 in chicken (LadjaliMohammedi et al. 1999). Species of Paleognathae birds (Pterocnemia pennata, Dromaius novaehollandiae, Casuarius casuarius, Struthio camelus and Rhea americana) also show only one pair bearing 18S-28S rDNA (Nishida-Umehara et al. 2007).

The Mimida e family comprises more than 30 species, where only Mimus saturninus (Lucca 1974) and Toxostomarufum (Jovanovic 1969) have been described cytogenetically. In these studies chromosome banding was not performed, being described only the diploid number and morphology of the macrochromosomes for both species and the $\mathrm{Z}$ sex chromosome for Toxostoma rufum. Considering this context, our aim was to perform a cytogenetic analysis of the species Mimus saturninus through classical cytogenetic methods including identification of constitutive heterochromatic regions and nucleolus organizer regions.

\section{MATERIAL AND METHODS}

One female and one male chick of Chalkbrowed Mockingbird (Mimus saturninus)were sampled for this study. They were collected at the Experimental Farm of the Federal University of Pampa, located in Dom Pedrito, Rio Grande do Sul State (RS), Brazil (Fig. 1). 
A

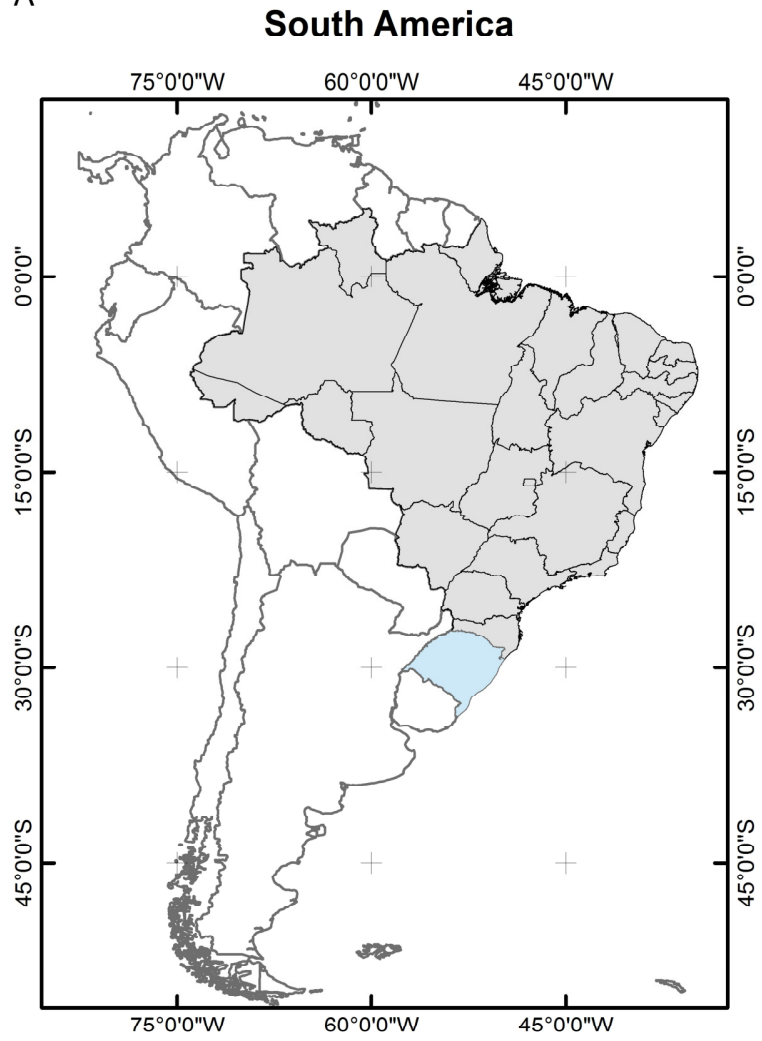

B

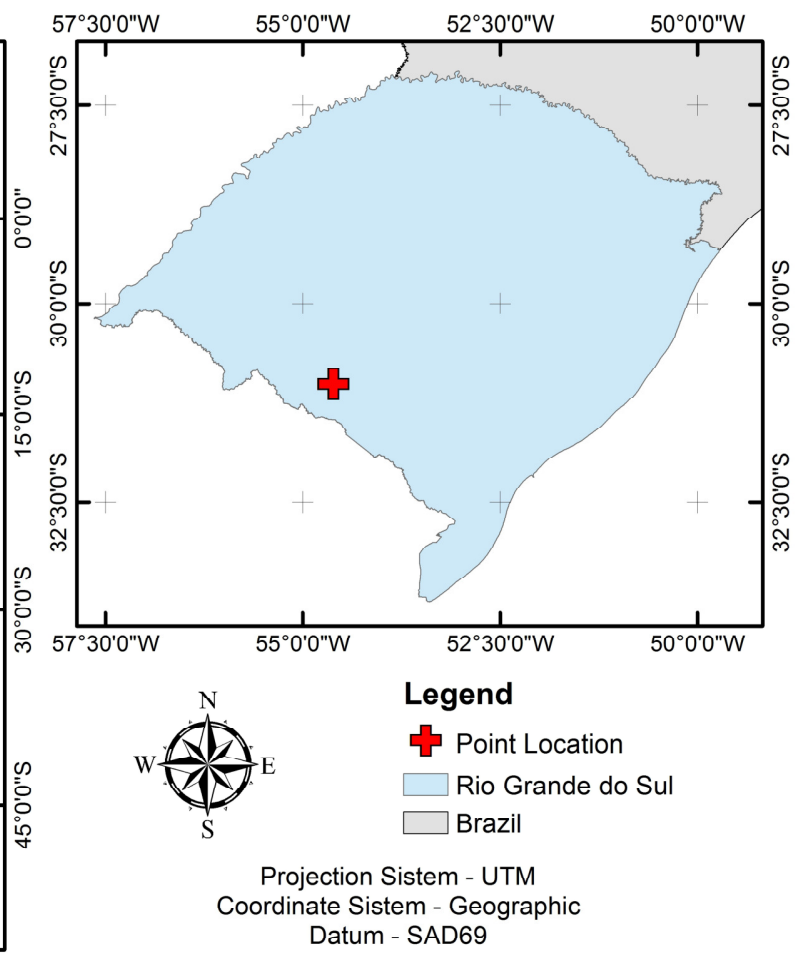

Figure 1 -Geographical location of the Experimental Farm in the Federal University of Pampa, Dom Pedrito, RS, Southern Brazil: a) Geographical map of South America, showing in gray the country Brasil and in blue the State of Rio Grande do Sul; b) Geographic map of the State of Rio Grande do Sul; Source: ArcGis 10.1 and Google Earth.

\section{Chromosome preparation}

Short-term culture from kidney cells was performed in order to obtain metaphase chromosomes. The kidney was suspended in 10 $\mathrm{ml}$ of Hank's solution with $0.1 \mathrm{ml}$ of $0.05 \%$ colchicine, followed by incubation at $37^{\circ} \mathrm{C}$ for 1 hour. After this time, the suspension was centrifuged at $800 \mathrm{rpm}$ for $8 \mathrm{~min}$ and the supernatant was removed. The pellet was resuspended in hypotonic $\mathrm{KCl}$ solution $(0.075 \mathrm{M}$, $10 \mathrm{ml}$ ) and incubated at $37{ }^{\circ} \mathrm{C}$ for more 30 minutes. Thereafter, the suspension was centrifuged at $800 \mathrm{rpm}$ for $8 \mathrm{~min}$ and the supernatant discarded again. The pellet was fixed in methanol and acetic acid (3:1) and centrifuged for the same speed and time, this step was repeated three times.

Giemsa staining, Ag-NORs, GTG- and CBG-banding

To determine the diploid number, 50 metaphases were analyzed in 5\% Giemsa staining. The identification of constitutive heterochromatin regions (CBG-banding) was performed according to Ledesma et al. (2002). To identify the chromosome pair carrying NORs it was used slides aged at $60{ }^{\circ} \mathrm{C}$ for 24 hours, subsequently it was done the silver staining according to the protocol of Howell and Black (1980). GTGbanding with trypsin was performed according to Seabright (1971).

\section{RESULTS AND DISCUSSION}

The karyotype of Mimus saturninus presents $2 n=80$, where the first and fourth pairs are submetacentric and the second, third and fifth are acrocentric, the other autosome chromosomes are telocentric. The $\mathrm{Z}$ sex chromosome is submetacentricand the $\mathrm{W}$ is metacentric (Fig. 2 a-b). This karyotype is typical of birds, which have a high diploid number ( $2 \mathrm{n}=$ among 78 and 80 ), a few pairs of macrochromosomes and many pairs of microchromosomes (Christidis 1990). The sex 
chromosomes of Mimus saturninus present the $\mathrm{Z}$ and $\mathrm{W}$ typical for Carinatas, which usually have significant differences in size and morphology as it is showed in other studies (Gunski et al. 2000,Stiglec et al. 2007, Correia et al. 2009).

The GTG-banding was similar to Gallus gallusand other bird species studied by Takagi and Sasaki (1974). Takagi and co-worker(1974) have shown an almost identical G-banding pattern in the three first pairsin nine species of different orders (Casuariiformes, Rheiformes, Ciconiiformes, Pelecaniformes, Anseriformes, Falconiformes, Phoenicopteriformes, Gruiformes and Galliformes). In Cathartiformes, the GTG-banding also showed very similar patterns in three species of theCathartidae family (Tagliarini et al. 2009). a)

c)

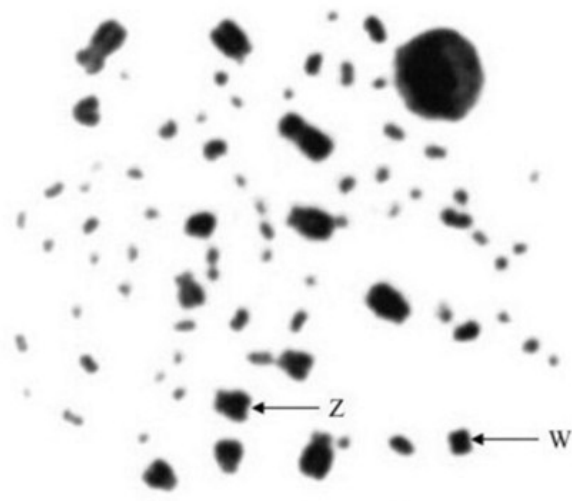

b)

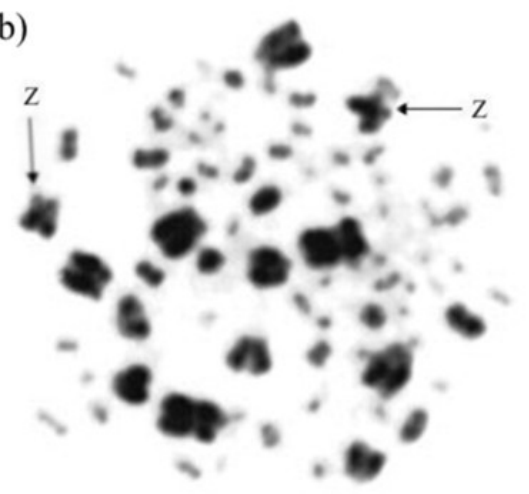

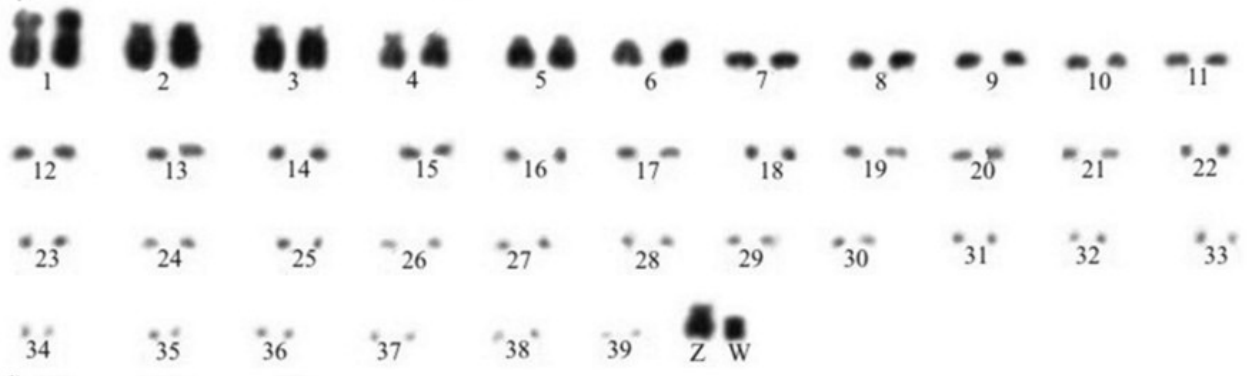

d)

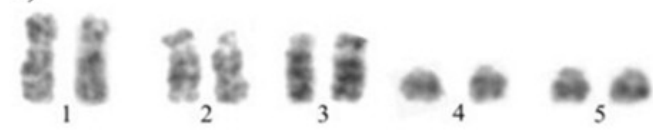

Figure 2 - Characterization of Chalk-browed Mockingbird (Mimus saturninus) karyotype by classical cytogenetics: (a) female metaphase by conventional Giemsa-staining, arrows show the $\mathrm{Z}$ and $\mathrm{W}$ sex chromosomes with differences in size and morphology; (b) male metaphase by conventional Giemsa-staining, arrows show the $\mathrm{Z}$ sex chromosomes; (c) Complete karyotype, 2n=80; (d) Macrochromosomes 1-5 GTG-banded.

The only species of the Mimidae family described (Toxostomarufum, $2 \mathrm{n}=78$ ) has a diploid number close to the Mimus saturninus, however, it differs in the morphology of some macrochromosomes pairs (fourth to tenth) and in the $\mathrm{Z}$ sex chromosome (metacentric). The $\mathrm{W}$ sex chromosome from Toxostomarufum was not identified (Jovanovic 1969).
In the CBG-banding we observed positive staining in the pericentromeric region of most macrochromosomes and microchromosomes, including in the $\mathrm{Z}$ sex chromosome, while in the W sex chromosome it was totally heterochromatic (Fig. 3). According to the classification proposed by Imai (1991) the species studied here is included in the Type I, once it has only pericentromeric CBG-banding, 
except in the $\mathrm{W}$ sex chromosome, which is totally heterochromatic. Type I classification includes mammals, fish and ants and Type II includes amphibians, grasshoppers and plants. Type I is characterized by constitutive heterochromatin presence in the region pericentromeric, while Type II is characterized by interstitial or terminal CBG-banding. The location data of constitutive heterochromatin in birds show pericentromeric and interstitial CBG-

a)

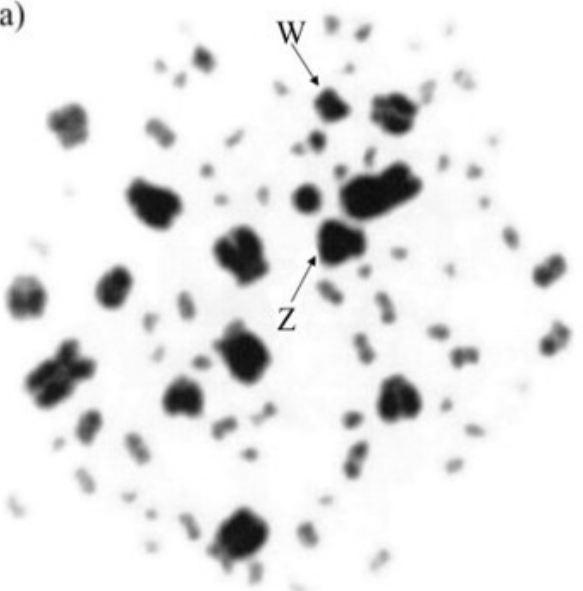

banding, thus birds may be classified in both groups (I or II). Constitutive heterochromatin can be observed in pericentromeric region of Ramphocelu scarbo (Correia et al. 2009), Tangara cayana and Tachyphonus rufus (Correia et al. 2009), while in Pheucticus aureoventris it was observed pericentromeric and interstitial CBG-banding (Ledesma et al. 2006).

b)

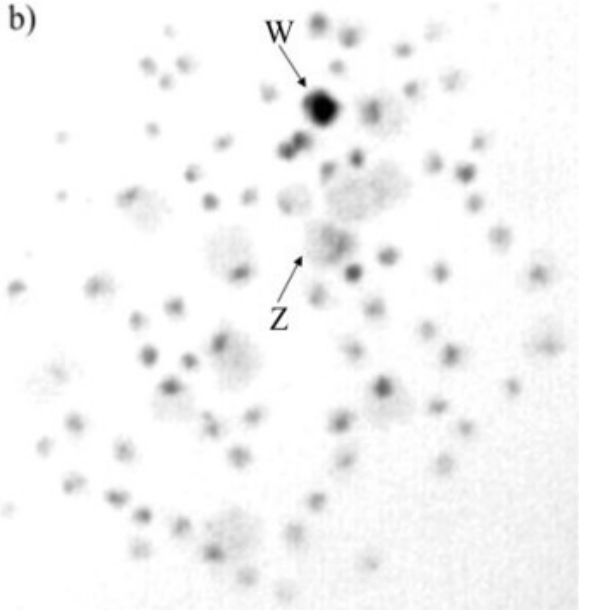

Figure 3 - Sequential analysis by conventional Giemsa and CBG-banding staining of metaphase from Mimus saturninus: (a) conventional Giemsa staining; (b) CBG-banding showing positive staining in the pericentromeric region of macrochromosomes, microchromosomes and in the $\mathrm{Z}$ sex chromosome. Note that the $\mathrm{W}$ sex chromosome it was totally heterochromatic. Arrows show the sex chromosomes $\mathrm{Z}$ and W.

The silver staining revealed one pair of microchromosome bearing NORs. This microchromosome pair has a secondary constriction below the centromere (Fig. 4). Because of the presence of secondary constrictions, Lucca and Rocha (1992) inferred that the species Mimus saturninus could have macro and microchromosomes involved in the organization of the nucleolus, which was not confirmed in ours Ag-NORs results. 
a)

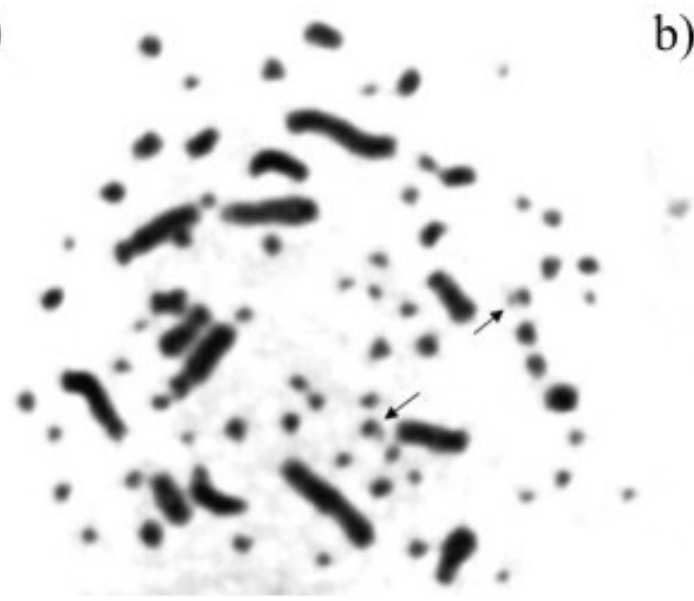

b)

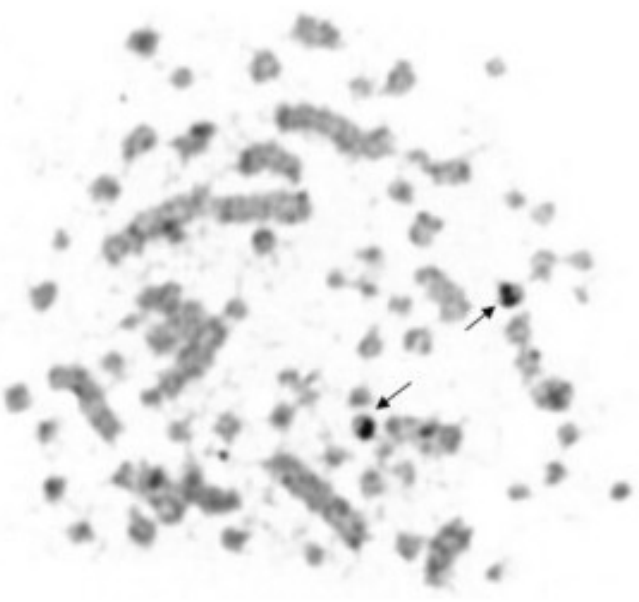

Figure 4 - Chromosomal distribution of the nucleolar organizer regions (NORs) on metaphase spreads of Mimus saturninus: (a) Conventional Giemsa staining; (b) Silver staining. Arrows show onemicrochromosomepair bearing NORs.

It is possible to suggest that Mimus saturninus has a plesiomorphic state in relation to the ancestral birds karyotype because the NORbearing is expressed in just one pair of microchromosome. This hypothesis is based on the fact that in Gallus gallus NOR-bearing corresponds to only one microchromosme pair (Ladjali-Mohammedi et al. 1999) as seen in the studied species considered Paleognathas, such as Rhea americana, Crypturellus tataupa, Tinamus solitarius, Pterocnemia pennata and Eudromia elegans (Gunski and Giannoni1998, Garnero et al. 2006, Nishida-Umehara et al. 2007). Some species from Passeriformes order also show this characteristic, as Tangara cayana (Correia et al. 2009), Furnarius rufus and Turdus albicollis (unpublished data). On the other hand, some species of this order show a derived characteristic of NORs, for example, Sittasomus griseicapillus and Lepidocolaptes angustirostris have one pair of macrochromosome bearing NORs and Pheucticus aureoventris has two pairs of microchromosomes (Barbosa et al. 2013; Ledesma et al. 2006).

In conclusion, our results showed a similarity in the diploid number between the two species of the Mimidae family described so far, however, there are some differences between pairs of macrochromosomes. The data presented here contribute to the understanding of karyotype evolution and the evolutionary state of this group related to the ancestral bird karyotype. Certainly, it is necessary to study classical cytogenetic in other species of the Mimidae family in order to check if the NOR-bearing is a plesiomorphic state shared among this group.

\section{ACKNOWLEDGMENTS}

Authors would like to thank PROPESQ/UNIPAMPA for financial support and CAPES for the scholarships to Rafael kretschmer, and the staff of the research group "Animal Genetic Diversity" for the technical support.

\section{REFERENCES}

Aguiar, MLR. Técnicas de cultura de tecidos para estudo dos cromossomos em aves. Cienc Cult. 1965, 17:587-590.

Barbosa MO, da Silva RR, Correia VCS, Santos LP, Garnero ADV, Gunski RJ. Nucleolar organizer regions in Sittasomus griseicapillus and Lepidocolaptes angustirostris (Aves, Dendrocolaptidae): Evidence of a chromosome inversion. Genetics and Molecular Biology. 2013, 36 (1) 70-73.

Christidis L. Aves, in John B (ed): Animal Cytogenetics, Vol 4, Chordata 3. Gebrüder Bornträger, Berlin, 1990.

Correia VCS, Garnero AV, Santos LP, Silva RR, Barbosa M, Bonifácio HL, Gunski RJ. Alta similaridade cariotípica na família Emberezidae 
(Aves: Passeriformes). BioscienceJournal. 2009, 25: 99-111.

De Oliveira EHC, Habermann FA, Lacerda O, Sbalqueiro IJ, Wienberg J, Müller S. Chromosome reshuffling in birds of prey: the karyotype of the world's largest eagle (Harpy eagle, Harpiaharpyja) compared to that of the chicken (Gallus gallus). Chromosoma. 2005, 114: 338-343.

De Oliveira EHC, Tagliarini MM, Nagamachi CY, Pieczarka JC. Comparação genômica em aves através de sondas cromossomo-específicas. Revista Brasileira de Ornitologia. 2006, 14 (1) 47-52.

Garnero AV, Ledesma MA, Gunski RJ. Alta homeologiacariotípica na família Tinamidae (Aves: Tinamiformes). Revista Brasileira de Ornitologia. 2006, 14 (1) 53-58.

Gunski RJ, Giannoni ML. Nucleolar organizerregionsand a new chromosomenumber for Rhea americana (Aves: Rheiformes). Genetics and Molecular Biology. 1998, 21(2):207-210.

Gunski RJ, Cabanne GS, Ledesma MA, Garnero AV. Análisis cariotípico de sieteespecies de Tiránidos (Tyrannidae). Hornero.2000, 15:103109.

Guyer, MF. Spermatogenesis of normal and hybrid pigeons. Dissertation (Doctor of Philosophy), Chicago, The University of Chicago, 1900.

Howell, WM, Black DA. Controlled silver staining of nucleolus organizer regions with a protective colloidal developer: a 1-step method. Experientia.1980, 36:1014-1015.

Imai, H. T. Mutability of constitutive heterochromatin (C-bands) during eukaryotic chromosomal evolution and their cytological meaning. Japanese Journal of Genetics. 1991, 66:635-661.

Ladjali-Mohammedi K, Bitgood JJ, TixierBoichard M, Ponce de Leon FA. International System for Standardized Avian Karyotypes (ISSAK): standardized banded karyotypes of the domestic fowl (Gallus domesticus). Cytogenetics and Cell Genetics. 1999, 86:271276.

Ledesma, MA, Garnero AV, Gunski RJ. Análise do Cariótipo de duas espécies da Família Formicariidae (Aves: Passeriformes). Ararajuba. 2002, 10:15-19.

Ledesma MA, Martínez PA, Calderón PS, Boeris JM, Meriles JM. Descrição do cariótipo e padrões de bandas C e NOR em Pheucticus aureoventris (Emberizidae, Cardinalinae). Revista Brasileira de Ornitologia. 2006, 14 (1) 59-62.

Lucca EJ. Cariótipo de oito espécies de aves. Revista Brasileira de Biologia. 1974, 34 (3) 253-263.

Lucca, EJ, Rocha GT. Citogenética de Aves. Bol Mus Para Emílio Goeldi sér Zool. 1992. 8:3367.

Masabanda, JS, Burt DW, O'brien PCM. Molecular cytogenetic definition of the chicken genome: the 1rst complete avian karyotype. Genetics. 2004, 166:1367-1373.

Nishida-Umehara C, Tsuda Y, Ishijima J, Ando J, Fujiwara A, Matsuda Y, Griffin DK. The molecular basis of chromosome orthologies and sex chromosomal differentiation in palaeognathous birds. Chromosome Research. 2007, 15:721-734.

Jovanovíc, V. Karyotypes of Four Passerine Birds Belonging to the Families Turdidae, Mimidae, and Corvidae. Chromosoma (Berl.). 1969, 26, 388-394.

Pieczarca, JC, Nagamachi CY. Pintura cromossômica como instrumento para estudos filogenéticos em primatas, p. 115-132. Em: M. Guerra (ed.). FISH: Conceitos e Aplicações na Citogenética. Ribeirão Preto: Sociedade Brasileira de Genética, 2004.

Raudsepp T, Houck ML, O'Brian PC, Fergunson-Smith MA, Ryder OA, Chowdhary BP. Cytogenetic analysis of California Condor (Gymnogyps californianus) chromosomes: comparison with chicken (Gallus gallus) 
macrochromosomes. Cytogenetic Genome Research. 2002, 98:54-60.

Santos LP, Gunski RJ. Revisão de dados citogenéticos sobre a Avifauna brasileira. Revista Brasileira de Ornitologia. 2006, 14 (1) 35-45.

Seabright M. A rapid banding technique for human chromosomes. Lancet. 1971, 2:971-972.

Stiglec R, Ezaz T, Graves JAM. A new look at the evolution of avian sex chromosomes. Cytogenetic and Genome Research. 2007, 117:103-109.

Tagliarini MM, Nagamachi CY, Pieczarka JC, Rissino $\mathrm{J}$ and de Oliveira EHC. Chromosomal analysis in Cathartidae: Distribution of heterochromatic blocks and rDNA, and phylogenetic considerations. Genetica.2009, 135:299-304.

Takagi N, Sasaki M. A phylogenetic study of bird karyotypes. Chromosoma.1974, 46: 91120.

Recebido: 05/08/2013 